\title{
Socio-philosophical Substantiation of Making Good Use of Intellectual and Creative Resources in a Teachers' Training Institution of Higher Education
}

\author{
Elena Nikolaevna Rodina ${ }^{1} \&$ Elena Nikolaevna Chekushkina ${ }^{1}$ \\ ${ }^{1}$ FSBEI HPE “The Mordovian State Pedagogical Institute named after M. E. Evseviev", Saransk, Russian \\ Federation \\ Correspondence: Elena Nikolaevna Rodina, FSBEI HPE "The Mordovian State Pedagogical Institute named \\ after M. E. Evseviev", Saransk, Studencheskay street, 11 A, 430007, Russian Federation. E-mail: \\ elenachekushkina@yandex.ru
}

Received: October 20, 2014

Accepted: November 27, 2014 Online Published: February 25, 2015

doi:10.5539/ass.v11n6p111

URL: http://dx.doi.org/10.5539/ass.v11n6p111

\begin{abstract}
The article dwells upon the experience of organizing out-of-school work of the Chair of Philosophy at Mordovian State Teachers' Training Institute named after M. E. Evseviev. The work is based on operation of a students' philosophic research club. The main goal of club's activities is to form social, cognitive, informative competency of personality achieved by means of development of scientific thinking, creativity, tolerance, sociability, humanism; to integrate the students' group and create a team based on joint scientific activities that contribute to further use of working skills in professional communities. This kind of work is organized as an addition to in-class work for solving topical issues of forming students' professional competency in a teachers' training institute of higher education.
\end{abstract}

Keywords: philosophical club, research work, professional competency, social introspection, creative work

\section{Introduction}

The modern day education is an institutionfor developing intellectual and creative resources of personality, makes it possible to use fundamental knowledge and principles in wide and unpredicted situations, helps to project behaviour strategies, encourages carrying on a dialogue and interacting with other people.

To have a successful career, it is insufficient to have a certain set of knowledge. It is necessary to be able to use the knowledge under the conditions of the fast changing reality. In their work, people must be oriented to innovative development as a constantly renewable process of creating novelties in all spheres of society. The growth of a flow of produced innovations turns into a stable social necessity. The society cannot satisfy this need at the expense of individual creative achievements, since innovative development is based not only on invention of something new, but also on its promotion to the sphere of consumption. That's why innovative activities must become massive and be designated as a significant social resource. As is known, most global revolutionary changes are prepared and realized by joint efforts of a certain number of people.

The present requires forming innovative qualities, such as abilities to size up non-standard, uncertain situations, abilities for self-development, self-education, motivation for innovation, for comprehension of existence and one's own being with the account taken of pressing social needs. The Higher School is intended to give students knowledge and form certain skills, axiological directions that are adequate to modern sociocultural conditions. H. Smith, an American sociologist, thinks that electronic computer means are less significant than human resources, since the development of technology that has become one of the most important ways of existence of modern societies in a competitive environment is ineffective without relevant development of human resources (Smith, 1995).

The Institute of Higher Education must be oriented not only towards training highly skilled specialists, but also towards making up a personality able for existential search, dialogue, social introspection and consensus. In the light of the problem of students' adaptation to conditions of studying in an institute of higher education observed by I. B. Buyanova, what is also important is work on the problem, which, according to the scientist, should be 
purposeful and systematic, implemented in compliance with the requirements of the times. A special role is assigned to out-of-school work and renovation of its forms (Buyanova, 2013).

It is possible to solve such problems by means of introducing students to studying the vast heritage of the world's philosophic thought, which contributes to development of interpretation skills, creative abilities, logical thinking, and moral culture. In practice, it is realized by means of out-of-school work of the Chair of Philosophy at Mordovian State Teachers' Training Institute named after M. E. Evseviev. It implies holding competitions, contests of research projects, creative works, essays, seminars, round-table discussions, monitoring intellectual resources, etc. What is also powerful is such a form of organizing out-of-school activities as a philosophical club.

The tradition of introducing students to research activities through friendly scientific societies exists in the history of the Russian Higher School since the 80s of the 18th century. The first was Assembly of University's Alumna for Exercising in Composition and Translation at Moscow University, students' Mathematical Society created in 1810 at the Faculty of Mathematics and Sciences. In the second decade of the 19th, students' Societies of Sciences, law societies, societies of literature and aeronautic slovers, scientific and literary, historical and literary, technical societies became an essential part of the academic space at universities (Zetkina, 2011).

\section{Methods}

The article bases upon activity, communication, and axiological approaches, which reveal the correlation between multiple components of social existence: duty, freedom, dialogue, consensus, tolerance.

The mentioned approaches are defined concretely in socio-philosophical principle, the key approaches are principles of historicism, concreteness, integrity, development and objectivity.

The complexity of the subject of the research study predetermined the use of the following methods:

Comparative-historical method, used to comprehend multiple historical forms of development of a philosophical club;

Integrative method, focusing on development of independence, cognitive activities and students' interests;

Axiological method, connected with the formation of a axiological and motivational structure of the subject of cognition capable of setting criteria, norms, assessments and reference points of the activities for motivation for actions and deeds;

System analysis, forming an integral comprehension of the phenomenon under study.

\section{Results}

In 2003, a students' scientific entity, a philosophical club, was created by the Chair of Philosophy at Mordovian State Teachers' Training Institute named after M. E. Evseviev. Members of the club are teachers and postgraduate students of the Chair as well as students of all directions of training.

The main objective of the club's activities consists in forming social, cognitive, informative competence of personality realized by means of developing scientific thinking, creativity, tolerance, sociability, humanism; integration of the students' group and creation of a team based on joint scientific activities that contribute to further use of working skills in professional communities. It focuses on development of "an ability to problematize (i.e. understand and conceive the actual problem that hides behind the evidence of the knowledge obtained legal norm or notion of self) the learnt knowledge in order to solve real vital problems later: academic-cognitive, scientific research, professional-pedagogic. Stimulation in achievement of an effective result during the process of their solution should be connected with the formation of the position of culture generating subjectivity" (Shukshina, 2013).

In addition, formation of skills of critical information assessment is also important in order to avoid manipulative impact. According to Jean Baudrillard, "we live in the world where there is more and more information, and less and less meaning' (Baudillard, 1983). However, information, as a rule, is always rich in content, conveys certain content and almost always, explicitly or implicitly, evaluation of events or actions.

The global informative-communicative space, change of a series of axilogical directions, abundance of a variety of information, including (even in the first place) moral content, dooms people to impossibility of remembering the information, saying nothing of reflecting upon it. For a modern person, it is more difficult to figure out what is going on because of oversupply of the varying contradicting information and because of the manipulative impact when information is used as an ideological, political, economic or other tool. 
So, one of the objectives of the philosophical club is students' understanding most pressing problems of the modern society relying on original theories of trustworthy researchers who set an example for finding oneself in a flow of information.

Communication is the only medium where what is worth being called rationality is possible (Habermas, 1995). It is the phenomenon of communication that can be considered one of the main human values. According to M. M. Bakhtin, "the human existence itself (both external and internal) is the deepest communication. To be means to communicate" (Bakhtin, 1986). It is during the process of communication, event and co-creation when a person can really find oneself.

For rational communication (dialogue), there is a need for informative and existential interaction between the communicating parties by means of which comprehension occurs. M. Buber and M. Bakhtin attach universal significance to the dialogue. Like Buber, Bakhin thinks every person is a subject for communication. A person cannot be spoken of a person only can be addressed to. "It is impossible to grasp, see and comprehend the inner person by making the person an object for indifferent neutral analysis, it is impossible to grasp a person by merging with the person and feeling him either. No, to approach and open a person, to be more exact, to make a person expose oneself, is possible only by communicating, dialogically" (Bakhtin, 1972). A dialogue is interpreted as communication between the I and the Other, both parties' choosing a common direction of interaction.

To carry on a dialogue, there is a need for openness to another person. But, in Buber's opinion, it is impossible to be open to everybody. The main movement, according to Buber, is an essential action of a person that serves as a base for an essential behavior, i.e. the behavior that expresses the true I. The main movement in a dialogue is addressing (feeling the difference of the Other). Buber depicts feeling the difference and closeness of the Other as follows, "It seemed to me that my skin borders upon an element of the vitality itself, something what was not the I, not the I at all, not the usual I, but something perceivable Other, not just something other, but the Other truly itself, and yet it admitted me, trusted in me, simply communicated with me, like You and You" (Buber, 1999).

N. Luhmann, a famous German sociologist, examined the notion of communication containing the hypothesis on reflective self-reference. "In communication, it is a matter of convention to communicate of the communication itself too. It is capable of correcting itself retrospectively or arguing as if it were meant to say something what has been just imaged or seemed" (Luhmann, 2004).

J. Habermas's communicative conception focuses on analyzing the role of the communicative mind in the modern information society. The notion of communicative rationality, according to the philosopher, is connected with ethic principle of the social discourse (Habermas, 1995). The essence of communicative action consists in the necessity of finding and using rational mechanism for searching for ways to consensus. Mutual comprehension, recognition, argumentation, consensus are seen as essential elements of interaction between people. The subject comprehends his own course of life in terms of wealth, not reasonability. Introspection running in the subject's self-consciousness implies a dialogue. J. Habermas, in his communicative theory, proceeds from the prospects of mutual understanding and communicative participation (Chekushkina, 2014). The communicative rationality is necessary for good argumentation of one's opinions, convincing presentation of one's point of view. As a result, the problem solution becomes more precise and clearer, subjectivity is removed: convictions of one person or a group of people receive proper support of others and thus are objectivized (Rodina, 2013).

In a dialogue, according to the Russian philosopher M. M. Bakhtin, the I of a stranger is affirmed and, therefore, the proper I is affirmed also. To affirm the I of a stranger not as an object, but as another subject is a principle underlying a dialogue, existence, self-consciousness. Everything exposed in a dialogue is not a certain existence of a person, but the last result of his consciousness and self-consciousness, the last word on oneself and one's world. Perception and comprehension of the Other is not composed of peculiarities of the reality, but of the meaning of these features for himself, for his self-consciousness.

A dialogue can be understood and interpreted not only as a direct communication, but also as an indirect communication. Perception of the information conveyed includes the interaction between the recipient and text generating sense, decoding the system of signs and interpretation of the sense. M. M. Bakhtin stated that a literary work has a character of a dialogic opinion because not only the author, but also the reader has the right for a word. "An event from the text's life, i.e. its true essence is always developing at the turn of two consciousness's, two subjects" (Bakhtin, 1979). It is during the act of perception a text becomes a social fact performing its multiple social functions. A text, according to M. M. Bakhtin, as early as at the moment of its 
mergence anticipates a reaction of the Other, is expecting for an answer. A text cannot be considered ready until it is framed with a dialogizing context.

The consciousness of the subject who is perceiving does not only supplements the work, but also forms it indirectly thanks to anticipation of the audience's reaction supposed by the author. Texts are created for an audience conditioning the existence. Jauss introduces a notion of "horizon of expectation" (Aksyonov, 1999), which indicated a certain paradigm of perceiving works during this or that epoch that determines further development of a thought. A "horizon of expectation" is formed by different factors. Among them is world view, axiological attitude, conditioned by its belonging to certain historical and national types of culture, social and demographic groups generating a certain structure of consciousness influencing on the perception and assessment of texts.

Each act of interpretation updates the existence of a text carrying on a dialogue between the past and the present. A work is thought as an open system where sense and value are historically mobile and changeable, that is why no conclusions about it can be considered absolute and finally exhausted. In addition, during the process of reception, the one who is perceiving correlates his own notions with the notions of the author, agreeing or disagreeing, that is why such an interpretation is co-creation, a social action. A dialogue between the author and the audience is oriented through temporal and spatial borders opening a wide notional potential of the work. So, in practice it is necessary to use limitless possibilities of philosophic texts in forming student's landmarks in terms of the world views, social, personality and moral aspects as well as culture of thinking.

Mechanisms of practical realization of value guiding lines and notions mainly in the system of cognitive theory initiates a philosophical thought to interpret its nature, origin, forming, distribution. Professor L. A. Mikeshina notes that "epistemological problem consists in understanding how the subject's activities full of values can perform constructive functions in cognition... Activities of a value oriented subject of cognition... become the key determinative factor and main condition of receiving true objective knowledge in the sphere of scientific cognition" (Mikeshina, 2006).

V. A. Lektorsky pays attention to the fact that "practical and cognitive rationality is impossible without certain informative pre-requisites: without a notion of the world and ways of its comprehension, without reception of an axiological system, within the limits of which the goal of practical action is set. Meanwhile, notions of the world and cognition and accepted values turn out to be historically and culturally conditioned" (Lektorsky, 2012). A would-be professional must understand the meaning of culture as a form of existence and be guided by principles of tolerance, dialogue and cooperation in his activities.

Culture is a special setting that performs the role of an inner censor, which controls the person's psychic life. A. Maslow pointed out the presence of hierarchically integrated superior and inferior animilities in a person defining the superior as a spiritual life, rooted in biological nature of the species. This superior aspect of a human being is called meta-motivation and directs his living landmarks to superior values of existence stimulating the necessity of creation, conscious labour, responsibility, justice, kindness and beauty.

In M. M. Bakhtin's opinion, the main criterion of spirituality of a person is a deed. It united real actions and the ideal aspect of his motivation, called "position". The position characterized a person's world view as his attitude to superior values. Its realization in the action is "participation in kindness", "contribution to the saving power of the beauty", "existence in truth". The truth consists in self-defining work of every person, in "polyphonic complicity to one another inside the notional value field". True freedom and person's self-realization in ethic action rejects self-assertion of individuals-atoms. A truly free person can only be in the space of essential mutuality, mutual responsibility, i.e. "in polyphonic chronotope of together-existence" (Davidova, 1992).

One of the innovative technologies in use directed to organization of personality motivated cognitive activities of students is an interactive technology of training based on dialogic communication. This technology implies even involvement of each participant of the educational process in the cognitive process, feeling it as an event that is of great importance based on personal commitment capable of transforming student's motives, settings, behavior.

Formation of an active communicative environment implies exchange of knowledge, ideas, ways of activities, contributing to perfection of cooperation skills. Such skills are of special importance in the modern society, since creation of any innovative products is based not so much on creative achievements of highly talented people, as on the planned joint work of teams.

The advantage of common work is that is uses human resources with different types of creativity. Researchers have detected two types of creativity, one is connected with generating of ideas, the other is connected with a 
critical analysis and further development (Dilts, 2003; Savenkov, 2000). Common creation is characterized by the fact that the effect of joint efforts differs radically compared to a simple sum of effort of individual employees. All novelties are born in dialogue, productive discussion, where idea generators and their critics supplement each other. An idea evolves during the process of purposeful introspection, correlation of different point of view with the context of the task. The result of joint search is synthetizing what was proposed, discovering hidden connections and promotion of novelties by some individual, member of the team.

\section{Discussion}

Organization of the activities of the philosophical club implies creation of a program of research studies. The program of activities includes the following components: choice and substantiation of the subject, goals and objectives, creation of working hypotheses, formation of a theoretical base, organization of control and management.

The subject is chosen and substantiating in joint search, dialogue between the teachers and students who conclude on how the subject under study has high heuristic and ethic potential and corresponds to criteria of scientific and topical character.

This kind of work implies direct involvement of all the participants in the space of creation, since the result is not set from the very beginning, it forms during the process of collective interaction. At the same time, each participant expresses their own spiritual world, realizes their own innermost personal motives of self-realization.

An attribute of this kind of activities is freedom, since an ideal model of the future result is poly variant, is not determined unambiguously, each subject creates it. An ideal image of supposed product of activities and a relevant inner plan of actions form in the consciousness, a person created ideal forms of things that do not exist yet and a form of activities for realizing them. Freedom lets person overcome limits set by nature, widen and enrich the existence.

N. A. Berdyaev, author of philosophy of creation, thought of freedom as of its basis. The act of creation is inseparably linked with the act of introspection, since a person must be aware of oneself as God's image realized through the possibility of free creation. Without forcing a person to create God expects him to realize the essential meaning of creation, involvement in the common flow of finishing God's Creation of the World, theurgy. This kind of person's introspection shows him the way for "divine" freedom, which is intended to set the spirit free from the world's captivity with its additions and passions; the beauty born in a creative act is transition to other existence, overcoming the sinful nature of the creator (Berdyaev, 1989). In these terms, creation can be considered a moral action.

According to P. L. Lavrov, morality consists in the orientation of creation towards the person himself, in his realizing his own I and creation of an ideal notion of it (Lavrov, 1965). The philosopher observed that person's moral life began with the realization of his personal dignity, creation of moral idea and implied continuing development, which is truly realized by inner comprehension of its necessity that serves as the most important necessity.

For a person, moral is object, prospects of self-development, while a course of his behaviour relies on such categories as conscience, self-esteem, duty, kindness (contrary to evil). Its unusualness is revealed in one thin only; it is appropriate and useful in the system of education to the same extent as is the education itself, which is not just training, broadening one's mind, but also perfection, spiritual growth of the personality. Moral values motivate person's behaviour, give rise to its activities as well as are system constitutive factor of moral formation. Person's orientation to values contributes to forming positive traits in it, needs and deeds of high moral standards.

We believe that any activities have two stages. First is the stage of introspection, which results in realizing what corresponds to duty, responsibility. Second is the stage connected with will, desire, pursuit, which result in the behaviour originating from moral values mentioned above. Every person finds himself in a situation of choice; when choosing, a person creates oneself, orientating to freedom of other and being responsible in front of the entire mankind. "To choose oneself means to affirm value of what we choose because we can choose evil by no means" (Sartre, 1990). Philosophic-methodological substantiation of the club's work is a research project dedicated to realizing phenomena of social introspection and creation. A series of round-table discussions on this subject has been held, where students presented and approved the results of an independent scientific search.

During research study they formulated a series of hypotheses confirming that categories of introspection and creation are of special interest to the modern humanitarian knowledge. 
The basis of formation of a theoretical base is addressing conceptions of M. Buber, J.-P. Sartre, N. Berdyaev, N. Luhmann, J. Habermas, since modern social tendencies require formation of new norms, imperatives and values that are distributed through dialogue, co-creation, identification, consensus.

Conclusion. The work resulted in formation of approaches: activity, communicative, axiological, contributing to optimization of rational managing and controlling the club's activities. They help to correctly orientate in the modern global information space and form an integral view on reality.

The essence and special features of these approaches are realized thanks to the following functions: cognitive (performing the function of cognition); regulative (performing the function of behaviour and activities); communicative (formed and realized during the process of communication); creative (expressed in person's creative self-determination, self-expression); emotive (serving for expressing and exiting moral emotions), etc.

At present, of special interest are such problems as creation as a factor of sociocultural changes, formation of culture of family and gender relations, social introspection in educational space of an innovative higher educational institution, moral-axiological aspects of the phenomenon of deceit (lies), etc. They are most effectively studies by using interactive pedagogical technologies of formation of an active communicative practice. In this connection, subjects, as a rule, become active participants of the action.

\section{Summary}

So, organization of out-of-school work by the chair of philosophy at Mordovian State Teachers' Training Institute is based upon interactive technologies, which realize potential of each participant of the educational process creating an active communicative environment. It contributes to students' development of social competence based on comprehension of responsibility for contents and quality of activities in any sphere of life; cognitive competence oriented towards perfection of research practice; information competence letting optimize person's adaptation in the surrounding world and resistance to manipulative impacts from the outside. This kind of activities contributes to formation of person's moral consciousness through realization of one's own actions, culture and its grounds orientating towards solving problems of practical humanization of the world. It is capable of securing the mode of self-development as a strategic factor of living.

Practical value of the work of the philosophical club is defined by the fact that substantiated theoretical methodological provisions, conceptual, structural and functional models and recommendations substantiated in its activities can be used when organizing theoretical and empirical research studies of problems of socio-humanitarian education.

\section{Acknowledgements}

The work has been conducted by financial support of the Ministry of Education and Science of the Russian Federation within project 2.1.2 "Solution of complex problems of forming teacher's and psychologist's competence in the system of continuing education" of the Program of Strategic Development at Mordovia State Teachers' Training Institute for 2012-2016 years/.

\section{References}

Aksyonov, A. V. (1999). Out-of-determinedness and Dialogue (Philosophical and Aesthetic Heritage of M. M. Bakhtin in the Light of Problems of Receptive Aesthetics, 1st ed.). Dialogue, Carnival, Chronotope.

Bakhtin, M. M. (1972). Problems of Dostoyevsky's poetics. Moscow: Khudlit.

Bakhtin, M. M. (1979). Aesthetics of Literary Creation. Moscow: Iskusstvo.

Bakhtin, M. M. (1986). Aesthetics of Literary Creation. Moscow: Iskusstvo.

Baudrillard, J. (1983). In the Shadow of the Silent Majorities, or The End of the Social and Other Essays. NewYork: Semiotext(e).

Berdyaev, N. A. (1989). Philosophy of Freedom. The Meaning of Creation. Moscow: Pravda.

Buber, M. (1999). Two Types of Face. Moscow: AST.

Buyanova, I. B. (2013). Analysis of the Level of Students' Adaptation to the University Environment. Middle East Journal of Scientific Research, 17(9), 1237-1242.

Chekushkina, E. N. (2014). J. Habermas's Communicative Theory and Culture of Information Society. Theory and Practice of Social Development.

Davidova, G. A., \& Averintsev, S. S. (1992). M. M. Bakhtin as a Philosopher. Moscow: Nauka.

Dilts, R. (2003). NLP: Creativity Management. Saint Petersburg: Piter. 
Habermas, J. (1995). Moral Consciousness and Communicative Action. Cambridge: MIT Press.

Habermas, J. (1995). Theory of Communicative Action. Cambridge: Polity Press.

Lavrov, P. L. (1965). Philosophy and Sociology (in two volumes). Moscow: Mysl.

Lektorsky, V. A. (2012). Philosophy, Cognition, Culture. Moscow: Canon.

Luhmann, N (2004). The Society of Society. Society as a Social System. Moscow: Logos.

Mikeshina, L. A. (2006). Philosophy of Science. Moscow: Moscow International University Publishing House.

Rodina, E. N., \& Kotova, S. S. (2013). Role of Philosophy in Formation of Students' Professional Competence at Teachers' Training Higher Educational Institution. Herald of Chelyabinsk State Teachers' Training University.

Sartre, J. P. (1990). Existentialism is a Humanism. Twilight of the Idols. Moscow: Poiltizdat.

Savenkov, A. I. (2000). By Genius's Cradle. Moscow: Pedagogical Society of Russia.

Shukshina, T. I., \& Tatianina, T. V. (2013). Content and Processual-Technological Aspects of Training Masters at a Teachers' Training Higher Educational Institution (Humanitarian Sciences and Education).

Smith, H. (1995). Rethinking America. New York: Random House.

Zetkina, I. A., \& Zamkin, P. V. (2011). Student's Research Pedagogical Club: Experience of Organization and Work (Humanitarian Sciences and Education).

\section{Copyrights}

Copyright for this article is retained by the author(s), with first publication rights granted to the journal.

This is an open-access article distributed under the terms and conditions of the Creative Commons Attribution license (http://creativecommons.org/licenses/by/3.0/). 